\title{
QUALITY OF LIFE ASSESSMENT IN PATIENTS UNDERGOING HEMODIALYSIS IN DUHOK CITY
}

\author{
MOHAMmed Hadar Musa \\ Dept. of Nursing, Technical Institute-Duhok, Kurdistan Region-Iraq
}

(Received: January 26, 2017; Accepted for publication: May 3, 2017)

\begin{abstract}
:
A descriptive study was conducted at the Duhok kidney and diseases transplantation center in order to assess the quality of life among (87) patients attend to Duhok kidney and diseases transplantation center. .The results of the study showed that there are tangible problems in all domains of Q.o.L whereas the physical domain comes first in rank, and statistically significant correlation between the all domains of Q.o.L and some variables like (sex, married status, education level and income level).
\end{abstract}

KEYWORDS: Quality, Assessment, Physical domain, Psychological domain, Social domain, Environmental domain.

\section{INTRODUCTION}

$\mathbf{T}$ he number of the people suffering from kidney failure is progressively on the rise every year and accretion in incidence and appearance of this disease has been recorded more than some years ago [1],

Hemodialysis (HD) is the major type of renal replacement for patients with End Stage Renal failure (E.S.R.F.)2

Hemodialysis patients are appending on dialysis and their quality of life is affected in defiance of physical and emotional problems, to get dialysis three times a week should be counted as part of their daily life, frequent use of dialysis machines causes loss of freedom and wasting time and high dependence on health care providers and other people [3].

End Stage Renal Failure (ESRF) is an increasing problem, and majority of the dialysis patients undergoing many problems [4].

End Stage Renal Failure (ESRF) is a cumulative, chronic disease that demands nursing and medical interventions which include hemodialysis (HD), or kidney transplant. Dialysis affects the quality of life, leading to restriction in activities and high level of disability and impairment in functioning status and psychosocial aspects [5].

Overall, end-stage renal disease patient has to cope with many adversities, like physical symptoms, special diet schedules, changes in their body image while the outcome of treatment is not standard [6].

End-stage renal disease is esteemed to have important effects on the patients' QoL and may affect negatively the social, financial and psychological aspects of their life [7].

Because of an increase in survival rates for patients with end stage renal disease, HRQoL has become progressively important as an outcome measure in the evaluation of dialysis treatments. [8]

QoL of patients with end stage renal failure (ESRF) is affected by the disease itself and by the type of substitution therapy. Many studies have recognized the effect of such factors as anemia, age, and depression on QOL (9).

Quality of life assessment is a basic factor of health-care estimation and helps in obtaining relevant procedures to increase the QOL of ESRF patients. 10

\section{Objective of the study:}

1-Identify socio-demographic characteristic of patients with chronic hemodialysis.

2- Quality of life assess at hemodialysis patients including four domains (physical, psychological, social, and environmental).

3- Find out the association between quality of life domains and sociodemographic (Age, sex, educational level, marital status, and income, duration of dialysis treatment and hours of dialysis) of study participants. 


\section{Methodology:}

A descriptive study was conducted at the Duhok kidney and diseases transplantation center in order to achieve the objectives of the study. The study was carried out among (125) patients, (87) patients were included criteria while (38) patients were distant from the study (14 patients with positive hepatitis, (5) patients lower than 18 years and (19) patients aggravation of physical conditions at the time of the study).

\section{Instruments construction:}

For the purpose of the present study, an instrument of two parts was constructed to assess QoL of patients with hemodialysis

Part1:

Included the independent variables like, sex, place where growing up, education level, marital status, income level, duration of dialysis treatment and hours of dialysis.

\section{Part2:}

QOL was designed by the World health organization instrument of quality of life (WHOQOL-BREF) ${ }^{11}$ questionnaire comprised of 26 items, to evaluate the quality of life among patients of hemodialysis.

The questionnaire of the present study is arranged into four domains including (physical, psychological, social and environmental domains).

\section{Calculating of quality of life}

Quality of life for patients was determined throughout the calculation of the score cut of point to bad (1-3), good $(3<-5)$.

\section{Statistical analysis:}

1- Percentages were used to calculate the description of the sample.

2- Chi-square test was used to determine the correlation between the scores of domains \& variables were considered significant when $\mathrm{P} \leq 0.01$.

\section{Results:}

Table (1) demonstrates of the socio demographic characteristics of 87 patients undergoing hemodialysis that attend to Duhok kidney and diseases transplantation center. The table evident, the highest percentage of patients was female $(51.7 \%)$, also, $(51.7 \%)$ of the samples was rural. It also appear from the table that a high percentage of the sample (46\%) with no formal education. With regard to income level, it appears that majority of the sample (56.3\%) were with low income.
Regarding to duration of dialysis the highest percentage (64.4\%) remains (3) hours on dialysis machine.

With regards to the marital status the highest percentage $(71.3 \%)$ was married while the lowest percentage $(4.6 \%)$ was discovered.

Figure (1) demonstrates the suffering patients from all domains of quality of life (psychological, physical, environmental and social). The physical problems come first in rank (77.01\%), while the social problems are last in rank $(32.18 \%)$.

Frequency and percentage for all QoL domains

Table (2) shows the frequency and percentage of physical QoL domain as following bad QoL was (53) which were $(60.9 \%)$ and the good QoL was (34) which were $(39.1 \%)$. Concerning to the psychological QoL domain the bad QoL was (50) and which were $(57.5 \%)$ and good QoL is (37) which were $(42.5 \%)$. Regarding to the social QoL domain the frequency of bad was (28) which were $(32.2 \%)$ while good QoL was (59) which were $(67.8 \%)$. Moreover to the environmental QoL domain frequency the bad was (30) percentage was $(34.5 \%)$ and good was (57) and percentage is $(65.5 \%)$.

Association between socio-demographic variable with physical domain quality of life

Table (3) shows that the proportion of good QoL increase with male, good QoL for male is $(40.5 \%)$ compering to the female patients $(6.7 \%)$. The study results declare that there was significant association between gender and physical domain in $(\mathrm{p}=0.001)$. Concerning to Place where growing up the highest percentage which is $(31 \%)$ for urban were in good QoL compering to $(15.6 \%)$ for rural. There is non- significant association between Place where growing up and physical domain at $(\mathrm{p}=0.001)$. With regard to educational level the highest percentage which is $(81.8 \%)$ for university graduation of good QoL compering to $(0 \%)$ for no formal education and illiteracy is the lowest percentage of good QoL, the results of the study shows that there has been significant association between physical domain and educational level $(\mathrm{p}=0.001)$. Related to marital status the highest percentage is $(66.7 \%)$ for single of good QoL compering to married which is the lowest percentage $(6.5 \%)$, the of the study shows that there was significant relationship between marital status and physical domain at $(\mathrm{p}=0.001)$. Concerning to income the highest percentage is $(85.7 \%)$ for patients with high income which is good QoL compering to $(6.1 \%)$ for patients with 
low income is the lowest percentage, the result of the study shows that there has been significant association between physical domain and income at $(\mathrm{p}=0.001)$.

Regarding to the hours of dialysis the highest percentage of good QoL is (25.8\%) for four hours comparing to the lowest percentage for good QoL which is $(21.4 \%)$ for three hours dialysis. The finding of the study shows that there was nonsignificant relationship between hours of dialysis and physical domain at $(\mathrm{p}=0.001)$.

\section{Association between socio-demographic variable with Psychological domain quality of life}

Table (4) shows that the proportion of good QoL increase with male, good QoL for male is (40.5\%) comparing to the female patients (20\%). The study results declare that there was significant association between gender and psychological domain $(p=0.001)$. Concerning to Place where growing up the highest percentage which is (45.2\%) for urban were in good QoL comparing to (15. 6\%) for rural. There is non- significant association between Place where growing up and psychological domain at $(\mathrm{p}=0.001)$. According to educational level the highest percentage is $(53.8 \%)$ for middle school of good QoL comparing to no formal education which is the lowest percentage $(22.5 \%)$ of good QoL, the results for the study shows that there has been significant association between educational level and psychological domain $(\mathrm{p}=0.001)$. According to the marital status the highest percentage is (50\%) for divorced comparing to single which is the lowest percentage $(28.6 \%)$ of good QoL, the result of the study detect that there was significant relationship between psychological domain and marital status $(\mathrm{p}=0.001)$. Concerning to income the highest percentage is (32.7\%) for patients with low income which is good QoL comparing to $(25 \%)$ for patients with moderate income is the lowest percentage, the result of the study shows that there has been significant association between income and psychological domain at $(\mathrm{p}=0.001)$. Regarding to hours of dialysis the highest percentage of good QoL is (32.2\%) for four hours comparing to the lowest percentage for good QoL which is $(28.6 \%)$ for three hours dialysis. The exposure of the study shows that there was nonsignificant relationship between psychological domain and hours of dialysis at ( $\mathrm{p}=0.001)$.

\section{Association between socio-demographic variable with social domain quality of life}

Table (5) shows that the proportion of good QoL increase with female, good QoL for male is (68. 9\%) comparing to the male patients (66. 7\%). The study results declare that there was significant association between gender and social domain in $(\mathrm{p}=0.001)$. Concerning to place where growing up the highest percentage which is $(76.2 \%)$ for urban were in good QoL comparing to $(60 \%)$ for rural. There is significant association between place where growing up and social domain at $(\mathrm{p}=0.001)$. According to educational level the highest percentage which is $(100 \%)$ for illiterate of good QoL comparing to $(57.5 \%)$ for No formal education and illiteracy is the lowest percentage of good QoL, the results for the study shows that there has been significant association between educational level as well social domain at $(p=0.001)$ Related to marital status the highest percentage is (74.2\%) for married of good QoL comparing to divorced which is the lowest percentage $(50 \%)$, the of the study shows that there was significant relationship between marital status and social domain at $(\mathrm{p}=0.001)$. Regarding to income level the highest percentage is $(83.3 \%)$ for patients with moderate income which is good QoL compering to $(57.1 \%)$ for patients with high income is the lowest percentage, the result of the study detect that there is significant association between social domain and income level at $(\mathrm{p}=$ 0.001).

Regarding to the hours of dialysis the highest percentage of good QoL is (71.4\%) for three hours comparing to the lowest percentage for good QoL which is $(61.3 \%)$ for four hours dialysis. The finding of the study shows that there was nonsignificant relationship between hours of dialysis and social domain at $(\mathrm{p}=0.001)$.

\section{Association between socio-demographic variable with Environental domain quality of life}

Table (6) shows that the proportion of good QoL increase with male, good QoL for male is (71.4\%) comparing to the female patients (60\%). The study results declare that there was significant association between gender and environmental domain in $(\mathrm{p}=0.001)$. Concerning to Place where growing up the highest percentage which is $(69 \%)$ for urban were in good QoL compering to (62.2\%) for rural. There is significant association between place where growing up and environmental domain at $(\mathrm{p}=0.001)$. According to educational level the highest percentage which is $(100 \%)$ for illiterate of good QoL comparing to $(53.8 \%)$ for 
Middle school is the lowest percentage of good QoL, the results for the study shows that there has been significant association between educational level as well environmental domain at $(\mathrm{p}=0.001)$. Related to marital status the highest percentage is (75\%) for divorced of good QoL comparing to single which is the lowest percentage $(61.9 \%)$, the study shows that there was significant relationship between marital status and environmental domain at $(\mathrm{p}=0.001)$. Concerning to income the highest percentage is $(83.3 \%)$ for patients with moderate income which is good QoL comparing to $(57.1 \%)$ for patients with high income is the lowest percentage, the result of the study shows that there has been significant association between income and environmental domain at $(\mathrm{p}=0.001)$.

Regarding to the hours of dialysis the highest percentage of good QoL is (71\%) for four hours comparing to the lowest percentage for good QoL which is $(62.5 \%)$ for three hours dialysis. The finding of the study shows that there was significant relationship between hours of dialysis and environmental domain at $(\mathrm{p}=0.001)$.

Table (1):-Socio-demographic characteristics of the patients

\begin{tabular}{|c|c|c|}
\hline Variables & $\mathrm{F}$ & $\%$ \\
\hline \multicolumn{3}{|c|}{ Sex } \\
\hline Male & 42 & 48.3 \\
\hline Female & 45 & 51.7 \\
\hline \multicolumn{3}{|c|}{ Place where growing up } \\
\hline Urban & 42 & 48.3 \\
\hline Rural & 45 & 51.7 \\
\hline \multicolumn{3}{|c|}{ Level of education } \\
\hline No formal education & 40 & 46 \\
\hline Illiterate & 4 & 4.6 \\
\hline Primary school & 19 & 21.9 \\
\hline Middle school & 13 & 14.9 \\
\hline University or above & 11 & 12.6 \\
\hline \multicolumn{3}{|c|}{ Marital Status } \\
\hline Married & 62 & 71.3 \\
\hline Single & 21 & 24.1 \\
\hline Divorced & 4 & 4.6 \\
\hline \multicolumn{3}{|c|}{ level of income } \\
\hline Low & 49 & 56.3 \\
\hline Moderate & 24 & 27.6 \\
\hline High & 14 & 16.1 \\
\hline \multicolumn{3}{|c|}{ Hours of dialysis } \\
\hline 3 Hours & 56 & 64.4 \\
\hline 4Hours & 31 & 35.6 \\
\hline
\end{tabular}

Table( 2):-Frequency and percentage for all QoL domains

\begin{tabular}{ccccc}
\hline QoL categories & Domains & F & $\%$ \\
\hline Valid & Good & Physical & 34 & 39.1 \\
\cline { 3 - 5 } & $>3$ & Psychological & 37 & 42.5 \\
\cline { 2 - 4 } & & Social & 59 & 67.8 \\
\cline { 2 - 4 } & Environmental & 57 & 65.5 \\
\cline { 2 - 4 } & Bad & Physical & 53 & 60.9 \\
\cline { 2 - 4 } & $<3$ & Psychological & 50 & 57.5 \\
\cline { 2 - 4 } & & Social & 28 & 32.2 \\
\cline { 2 - 4 } & & Environmental & 30 & 34.5 \\
\hline
\end{tabular}




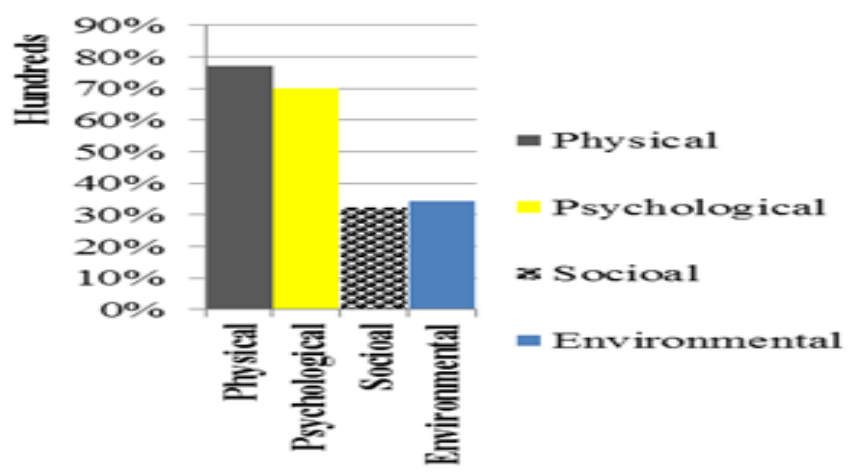

Figure (1):- Domains of quality of life problems

Table (3):-Association between socio-demographic variable with physical domain quality of life

\begin{tabular}{|c|c|c|c|c|c|c|}
\hline \multirow[t]{2}{*}{ Variables } & \multirow[t]{2}{*}{ No. } & \multicolumn{2}{|c|}{ Bad QoL } & \multicolumn{2}{|c|}{ Good QoL } & \multirow[t]{2}{*}{$\mathrm{x}^{2}$} \\
\hline & & No. & $\%$ & No. & $\%$ & \\
\hline \multicolumn{7}{|c|}{ Sex } \\
\hline Male & 42 & 25 & 59.5 & 17 & 40.5 & 14.03 \\
\hline Female & 45 & 42 & 93.3 & 3 & 6.7 & \\
\hline \multicolumn{7}{|c|}{ Place where growing up } \\
\hline Urban & 42 & 29 & 69 & 13 & 31 & 2.91 \\
\hline Rural & 45 & 38 & 84.4 & 7 & 15.6 & \\
\hline \multicolumn{7}{|c|}{ Education level } \\
\hline No formal education & 40 & 40 & 100 & 0 & 0 & 278.99 \\
\hline Illiterate & 4 & 4 & 100 & 0 & 0 & \\
\hline Primary school & 19 & 15 & 78.9 & 4 & 21.1 & \\
\hline Middle school & 13 & 6 & 46.2 & 7 & 53.8 & \\
\hline University or above & 11 & 2 & 18.2 & 9 & 81.8 & \\
\hline \multicolumn{7}{|c|}{ Marital Status } \\
\hline Married & 62 & 58 & 93.5 & 4 & 6.5 & 33.85 \\
\hline Single & 21 & 7 & 33.3 & 14 & 66.7 & \\
\hline Divorced & 4 & 2 & 50 & 2 & 50 & \\
\hline \multicolumn{7}{|c|}{ Income level } \\
\hline Low & 49 & 46 & 93.9 & 3 & 6.1 & 39.05 \\
\hline Moderate & 24 & 19 & 79.2 & 5 & 20.8 & \\
\hline High & 14 & 2 & 14.3 & 12 & 85.7 & \\
\hline \multicolumn{7}{|c|}{ Hours of dialysis } \\
\hline 3 Hours & 56 & 44 & 78.6 & 12 & 21.4 & 0.22 \\
\hline 4Hours & 31 & 23 & 74.2 & 8 & 25.8 & \\
\hline
\end{tabular}

Table( 4):-Association between socio-demographic variable with psychological domain quality of life

\begin{tabular}{|c|c|c|c|c|c|c|}
\hline \multirow[t]{2}{*}{ Variables } & \multirow[t]{2}{*}{ No. } & \multicolumn{2}{|c|}{ Bad QoL } & \multicolumn{2}{|c|}{ Good QoL } & \multirow[t]{2}{*}{$\mathrm{X}^{2}$} \\
\hline & & No. & $\%$ & No. & $\%$ & \\
\hline \multicolumn{7}{|c|}{ Sex } \\
\hline Male & 42 & 25 & 59.5 & 17 & 40.5 & 13.82 \\
\hline Female & 45 & 36 & 80 & 9 & 20 & \\
\hline \multicolumn{7}{|c|}{ Place where growing up } \\
\hline Urban & 42 & 23 & 54.8 & 19 & 45.2 & 4.43 \\
\hline Rural & 45 & 38 & 84.4 & 7 & 15.6 & \\
\hline \multicolumn{7}{|c|}{ Education level } \\
\hline No formal education & 40 & 31 & 77.5 & 9 & 22.5 & 274.15 \\
\hline Illiterate & 4 & 3 & 75 & 1 & 25 & \\
\hline Primary school & 19 & 14 & 73.7 & 5 & 26.3 & \\
\hline Middle school & 13 & 6 & 46.2 & 7 & 53.8 & \\
\hline University or above & 11 & 7 & 63.6 & 4 & 36.4 & \\
\hline
\end{tabular}




\begin{tabular}{|c|c|c|c|c|c|c|}
\hline \multicolumn{7}{|c|}{ Marital Status } \\
\hline Married & 62 & 44 & 71 & 18 & 29 & 30.58 \\
\hline Single & 21 & 15 & 71.4 & 6 & 28.6 & \\
\hline Divorced & 4 & 2 & 50 & 2 & 50 & \\
\hline \multicolumn{7}{|c|}{ Income level } \\
\hline Low & 49 & 33 & 67.3 & 16 & 32.7 & 34.97 \\
\hline Moderate & 24 & 18 & 75 & 6 & 25 & \\
\hline High & 14 & 10 & 71.4 & 4 & 28.6 & \\
\hline \multicolumn{7}{|c|}{ Hours of dialysis } \\
\hline 3 Hours & 56 & 40 & 71.4 & 16 & 28.6 & 2.16 \\
\hline 4Hours & 31 & 21 & 67.8 & 10 & 32.2 & \\
\hline
\end{tabular}

Table( 5):-Association between socio-demographic variable with social domain quality of life

\begin{tabular}{|c|c|c|c|c|c|c|}
\hline \multirow[t]{2}{*}{ Variables } & \multirow[t]{2}{*}{ No. } & \multicolumn{2}{|c|}{ Bad QoL } & \multicolumn{2}{|c|}{ Good QoL } & \multirow[t]{2}{*}{$\mathrm{X}^{2}$} \\
\hline & & No. & $\%$ & No. & $\%$ & \\
\hline \multicolumn{7}{|c|}{ Sex } \\
\hline Male & 42 & 14 & 33.3 & 28 & 66.7 & \multirow[t]{2}{*}{91.48} \\
\hline Female & 45 & 14 & 31.1 & 31 & 68.9 & \\
\hline \multicolumn{7}{|l|}{ Place where growing up } \\
\hline Urban & 42 & 10 & 23.8 & 32 & 76.2 & \multirow[t]{2}{*}{82.46} \\
\hline Rural & 45 & 18 & 40 & 27 & 60 & \\
\hline \multicolumn{7}{|c|}{ Education level } \\
\hline No formal education & 40 & 17 & 42.5 & 23 & 57.5 & \multirow[t]{5}{*}{346.22} \\
\hline Illiterate & 4 & 0 & 0 & 4 & 100 & \\
\hline Primary school & 19 & 4 & 21.1 & 15 & 78.9 & \\
\hline Middle school & 13 & 4 & 30.8 & 9 & 69.2 & \\
\hline University or above & 11 & 3 & 27.3 & 8 & 72.7 & \\
\hline \multicolumn{7}{|c|}{ Marital Status } \\
\hline Married & 62 & 16 & 25.8 & 46 & 74.2 & \multirow{3}{*}{107.56} \\
\hline Single & 21 & 10 & 47.6 & 11 & 52.4 & \\
\hline Divorced & 4 & 2 & 50 & 2 & 50 & \\
\hline \multicolumn{7}{|c|}{ Income level } \\
\hline Low & 49 & 18 & 36.7 & 31 & 63.3 & \multirow[t]{3}{*}{111.78} \\
\hline Moderate & 24 & 4 & 16.7 & 20 & 83.3 & \\
\hline High & 14 & 6 & 42.9 & 8 & 57.1 & \\
\hline \multicolumn{7}{|c|}{ Hours of dialysis } \\
\hline 3 Hours & 56 & 16 & 28.6 & 40 & 71.4 & \multirow[t]{2}{*}{80.28} \\
\hline 4 Hours & 31 & 12 & 38.7 & 19 & 61.3 & \\
\hline
\end{tabular}

Table( 6):-Association between socio-demographic variable with environmental domain quality of life

\begin{tabular}{|c|c|c|c|c|c|c|}
\hline \multirow[t]{2}{*}{ Variables } & \multirow[t]{2}{*}{ No. } & \multicolumn{2}{|c|}{ Bad QoL } & \multicolumn{2}{|c|}{ Good QoL } & \multirow[t]{2}{*}{$\mathrm{X} 2$} \\
\hline & & No. & $\%$ & No. & $\%$ & \\
\hline \multicolumn{7}{|c|}{ Sex } \\
\hline Male & 42 & 12 & 28.6 & 30 & 71.4 & 80.64 \\
\hline Female & 45 & 18 & 40 & 27 & 60 & \\
\hline \multicolumn{7}{|c|}{ Place where growing up } \\
\hline Urban & 42 & 13 & 31 & 29 & 69 & 71.93 \\
\hline Rural & 45 & 17 & 37.8 & 28 & 62.2 & \\
\hline \multicolumn{7}{|c|}{ Education level } \\
\hline No formal education & 40 & 16 & 40 & 24 & 60 & 335.2 \\
\hline Illiterate & 4 & 0 & 0 & 4 & 100 & \\
\hline Primary school & 19 & 6 & 31.6 & 13 & 68.4 & \\
\hline Middle school & 13 & 6 & 46.2 & 7 & 53.8 & \\
\hline University or above & 11 & 2 & 18.2 & 9 & 81.8 & \\
\hline \multicolumn{7}{|c|}{ Marital Status } \\
\hline Married & 62 & 21 & 33.9 & 41 & 66.1 & 90.27 \\
\hline Single & 21 & 8 & 38.1 & 13 & 61.9 & \\
\hline Divorced & 4 & 1 & 25 & 3 & 75 & \\
\hline
\end{tabular}




\begin{tabular}{|c|c|c|c|c|c|c|}
\hline \multicolumn{7}{|c|}{ Income level } \\
\hline Low & 49 & 20 & 40.8 & 29 & 59.2 & 100.25 \\
\hline Moderate & 24 & 4 & 16.7 & 20 & 83.3 & \\
\hline High & 14 & 6 & 42.9 & 8 & 57.1 & \\
\hline \multicolumn{7}{|c|}{ Hours of dialysis } \\
\hline 3 Hours & 56 & 21 & 37.5 & 35 & 62.5 & 69.82 \\
\hline 4Hours & 31 & 9 & 29 & 22 & 71 & \\
\hline
\end{tabular}

\section{DISCUSSION}

End-stage renal failure has severe effects on the patient's QOL, passively affecting their social, financial, and psychological well-being. ${ }^{12}$ Figure (1) demonstrate that the patients were suffering from all domains (physical, psychological, social, and environmental) of Q.o.L , the physical problems come first in rank

(77\%), while the social problems are last in rank $(32 \%)$.This result is in disagreement with (Shrestha S, et all, 2008), which shows in his study the social domain of QoL had the highest score, followed by the physical domain. ${ }^{13}$

Table (2) shows the frequency and percentage of physical QoL domain as following bad QoL was (53) which were $(60.9 \%)$ and the good QoL was (34) and (39.1\%). Concerning the psychological QoL domain the bad QoL was (50) and $(57.5 \%)$ and the good QoL is (37) and (42.5\%). Regarding the social QoL domain the frequency of bad was (28) which were $(32.2 \%)$ while the good QoL was (59) which were $(67.8 \%)$. Moreover the environmental QoL domain frequency the bad was (30) percentage is (34.5\%) and the good was (248) and percentage is $(62 \%)$ regarding the spiritual QoL domain the frequency of bad was (24) and percentage is $(6.0 \%)$ the good was (57) and percentage is $(65.5 \%)$.

Table (3) shows the significant relationship between gender and physical domain. Support for this finding was reported by (Alvares et al., 2014) who indicated that women had significantly lower scores than males in symptom burden scales (Physical Functioning, Bodily Pain, and Vitality) 14. According to the place of residence, our study shows that there are non-significant relationship between Physical domain and residence. No studies were found that estimate this variable and its relation with the QoL level, but the charge subscale is possibly determined by the faraway people need to travel from their place of residence, situated in rural areas, to the dialysis centers in the city. Regarding the level of education the present study found that there was significant relationship between the level of education and physical domain $(\mathrm{P}=0.01)$. This result was similar to the result done by (Sathvik BS al., 2008) who indicated the higher education had better quality of life, perhaps because education permit deep comprehension of the disease and compliance to the therapeutic regimen. ${ }^{15}$ Also, marital satus was significantly associated with QoL score. This result is in agreement with (Sagduyu et al,2006) who confirm a significant impact of marital status on QoL in dialysis patients. ${ }^{16}$ Concerning the level of income the present study shows that there was significant relationship between physical domain and this variable $(\mathrm{P}=0.01)$. The result of this study is also consistent with finding of (Mahboob L. et al, 2009) the study found no significant differences between income and KDQoL except for physical domain, it had no better score in patients with higher level of socioeconomical as compared to poor individuals $(p=0.05) .{ }^{17}$ With regard to the hours of dialysis, it revealed that there was non-significant differences among samples $(\mathrm{p}<0.01)$. This disagreement with the results of (Vasilieva IA, 2006) $\left({ }^{18}\right)$. Which indicates that duration of dialysis plays an important role QoL in dialysis patients.

Table (4) shows the significant relationship between gender and psychological domain $(\mathrm{P}=0.001)$. Support for this finding was reported by (Santos P, Franco L.., 2008) who indicated scored better than women on the symptoms, effects and mental functioning subscales and account of these differences, women score lower, due to the psychological aspect some authors consider determinant in this condition ${ }^{19}$. Concerning the place of residence, the result of the study shows that there was non-significant relationship between gender and psychological domain. Regarding to the level of education the present study found that there was significant relationship between the level of education and psychological domain $(\mathrm{P}=0.01)$. This result this is in agreement with (Díaz-Buxo J et al., 2000) which found a constructive correlation between all subscales and years of education. People with greater than eight years of education acquired preferable QoL scores than people with lower 
level of education. ${ }^{20}$ Also marital statuses was significantly associated with QoL score. This finding is in agreement with (Sagduyu et al,2006) who reported a significant effect of marital status on QOL in dialysis patients. ${ }^{16}$ The role of higher income is reflected in the higher scores in all domains of QOL, Our study results are consistent with findings of other studies that reported a positive association between family income and QOL scores. ${ }^{21}$ With regard to the hours of dialysis, it revealed that there was non-significant differences among samples at $(\mathrm{p}<0.01)$. This result is contradiction with the results of (Ismael $\mathrm{M}$ et al, 2005), which denote that duration of treatment and hours of dialysis were constructively related with the mental functioning subscale. ${ }^{2}$

Table (5) shows the significant correlation between social domain and gender. This result is in agreement with (Mahboob Lessan et al., 2009) who indicated there was significant correlation between male and female with physical function, social function as well as social function $(\mathrm{p}<0.001) .{ }^{17}$.

Table (5) shows non-significant relationship between residence and social domain $(\mathrm{P}=0.001)$.

Also, the result of the present study showed that there were significant relationship between the level of education and social domain $(\mathrm{P}=0.01)$. Another alternative explanation is that higher education may reflect higher income and consequently ability to afford treatment. Other studies shows favorable relation between quality of life and the level of education. ${ }^{23}$ The marital status was not significantly associated with QoL score. This finding is different from (Sagduyu et al,2006) who reported a significant effect of marital status on QOL in dialysis patients. ${ }^{16}$ Regarding to the income level) the present study found that there was significant relationship between these variable and physical domain $(\mathrm{P}=0.01)$. The result of this study is also consistent with finding of (Mahboob Lessan et al, 2009) the study found was no significant differences between income and KDQoL except for the role of physical, it had no better score in patients with higher level of socio-economical as compared to poor individuals $(\mathrm{p}=0.05) .{ }^{17}$ With regard to the hours of dialysis, it revealed that there were significant differences among samples at $(p<0.01)$. This result is in agreement with the results of (Vasilieva IA, 2006), which indicates that duration of dialysis plays an important role in affecting QOL in dialysis patients.

\section{CONCLUSION}

According to the objectives of the present study and the results of the data analysis, the following conclusions have been inferred:
1- There are tangible problems in all (physical, psychological, social and environmental) domains whereas the physical domain comes first in rank. 2- There were statistically significant correlation between the all domains of Q.o.L and some variables like (sex, marital status, education level and income level).

\section{REFERENCES}

- Henrich W L .Principles and Practice of dialysis. Philadelphia, LippincottWilliams \& Wilkins.2009.

- Victoria Alikari, Vasiliki Matziou, Maria Tsironi, Parskevi Theofilou and Sofia Zyga . The Effect of Nursing Counseling on Improving Knowledge, Adherence to Treatment and Quality of Life of Patients Undergoing Hemodialysis. International Journal of Caring Sciences May-August 2015 Volume 8 Issue 2 P. 514.

-Hagren B .Hamodialysis of suffering from end stage renal disease .Journal of advanced Nursing. 2001; (34)2:196 -202.

- Thomas D, Joseph J, Francis B, Mohanta GP (2009) Effect of patient counseling on quality of life of hemodialysis patients in India. Pharmacy Practice 7: 181- 184.

- Pollice R, Di Mauro S, Bernardini M, Bianchini V, Giordani Paesani N (2010) Psychopathology, quality of life and social functioning in dialysis treatment and kidney transplantation patients. Clin Ter 161: 329-333.

- Mavromates P. Physical activity and chronic renal failure. Dialysis Living 2005;13:22-38.

- Sarris M. Health sociology and quality of life. Athens: Papazisis, 2001.

- Cameron JI, Whiteside C, Katz J, Devins GM. Differences in quality of life across renal replacement therapies: a meta-analytic comparison.

Am J Kidney Dis 2000;35:629-37.

- Valderrabano F, Jofre R, and Lopez-Gomez JM.(2001): Quality of life in end-stage renal disease patients. Department of Nephrology, Hospital General Universitario Gregorio Marañón, Madrid, Spain. Am J Kidney Dis. 38(3), 443-64.

-Suja Abraham., Anju Venu1, Anju Ramachandran1, Praseetha Mundapurath Chandran1 and Saraswathi Raman3 Assessment of Quality of Life in Patients on Hemodialysis and the Impact of Counseling, Saudi Journal of Kidney Diseases and Transplantation, 2012;23(5):953957. 
-Skevington SM, Lotfy M, O'Connell KA. The World Health Organization's WHOQOL-BREF quality of life assessment: psychometric properties and results of the international field trial. A report from the WHOQOL group. Qual Life Res 2004;13(2):299-310.

- Christensen AJ, Ehlers SL. Psychological factors in endstage renal disease: an emerging context for behavioral medicine research. J Consult Clin Psychol. 2002;70:712-24

- Shrestha S, Ghotekar LR, Sharma SK, Shangwa

PM, Karki P. Assessment of quality of life in patient of end stage renal disease on different modalities of treatment. J Nepal Med Assoc 2008;7:1-6.

-Alvares J, Almeida A M, Szuster D Araujo Campos, Gomes IC, Andrade EI Gurgel, Acurcio F de Assis et al . Factors associated with quality of life in patients in renal replacement therapy in Brazil. Cien Saude Colet .2013[citado 2014 nov 27];18(7):1903-10.

-Sathvik BS, Parthasarathi G, Narahani MG, Gurudev KC. An assessment of the quality of life in hemodialysis patients using the WHOQOLBREF questionnaire Indian J Nephrol. 2008; 18(4): 141-149.

- Sagduyu A, Senturk VH, Sezer S, Emiroglu R, Ozel S. Psychiatric problems, life quality and compliance in patients treated with hemodialysis and renal transplantation. Turk Psikiyatri Derg 2006;17:22-31.
- Mahboob Lessan-Pezeshki1, Zohreh Rostami2. Contributing Factors in Health-Related Quality of Life Assessment of ESRD Patients: A Single Center Study. Int J Nephrol Urol, 2009; 1(2):129-136

-Vasilieva IA. Quality of life in chronic hemodialysis patients in Russia. Hemodial Int. 2006;10:274-8.

- Santos P, Franco L. Clinical and laboratory variables associated with quality of life in Brazilian haemodialysis patients: a single-centre study. Rev Med Chile. 2008;136(10):1264-71.

-. Díaz-Buxo J, Lowrie E, Lew N, Zhang H, Lazarus J. Quality-of-life evaluation using Short Form 36: comparison in hemodialysis and peritoneal dialysis patients. Am J Kidney Dis. 2000;35(2):293-300.

- Coelho-Marques FZ, Wagner MB, Figueiredo CE, Avila DO. Quality of life and sexuality in chronic dialysis female patients. Int $\mathrm{J}$ Impot Res. 2006;18:539-43.

- Ismael M, Bernardi C. Qualidade de vida de pessoas com doenca renal cronica em tratamento hemodialítico. Rev. Latino-Am. Enfermagem. 2005;13(5):670-6.

- Alshraifeen A, McCreaddie M, Evans JM. Quality of life and well-being of people receiving haemodialysis treatment in Scotland: A crosssectional survey. Int J Nurs Pract. 2014; 20(5): 518-523.

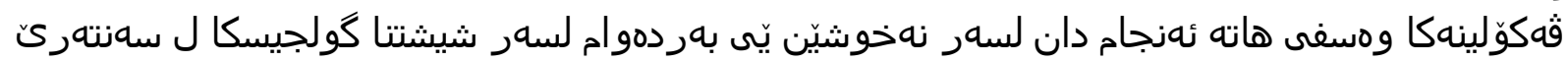

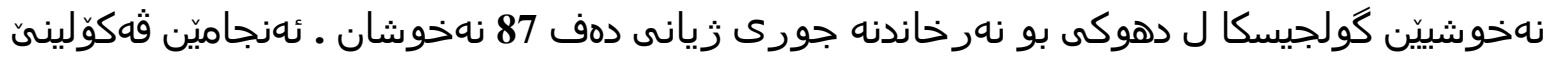

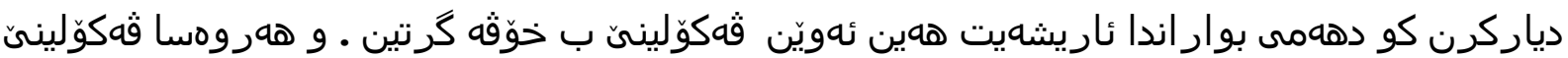

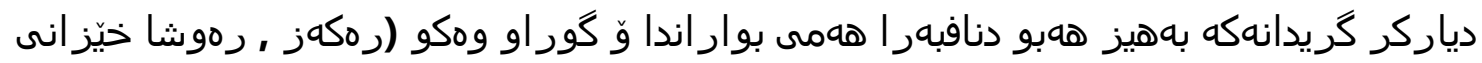

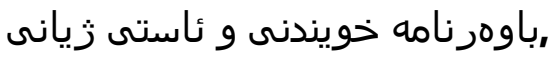

دراسة وصفية أجريت على المرضى المستمرين على غسل الكلية في مركز امراض ودرية إدرع الكلية في

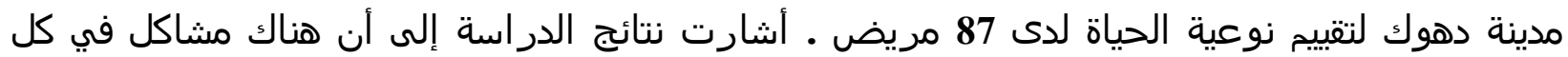

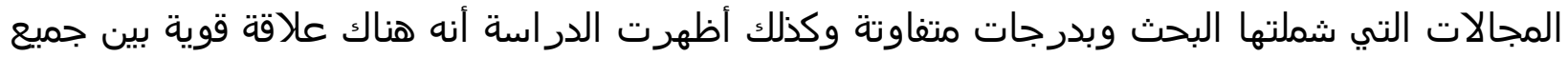
المجالات و بعض المتغيرات مثل (الجنس , الحالة الزوجية , مستوى التعليم والمستوى المعاش). 